\title{
PENGETAHUAN DAN SIKAP MASYARAKAT DALAM UPAYA PENCEGAHAN PENYAKIT SCHISTOSOMIASIS DI PUSKESMAS WUASA KABUPATEN POSO
}

\author{
Noviany Banne Rasiman ${ }^{1)}$, Lona Stanye Sampali2) \\ 1,2 STIK Indonesia Jaya Palu \\ E-mail: ophynkrasiman@yahoo.com
}

\begin{abstract}
Background: Schistosomiasis is a disease caused by Schistosoma japonicum worms that require an intermediary animal called Snail Oncomelania Hupensis Lindoensis. In the working area of Primary Health Care of Wuasa is the focus area of snails (habitat snail) which most of the inhabitants are migrants who open rice fields and plantations. Eradication of Schistosomiasis disease has not reached the target to $<1 \%$, because there are still many local communities have less supportive behaviors in terms of prevention. The objective of this study was to know knowledge and attitude of community in effort of prevention of Schistosomiasis disease at Health Primary Care of Wuasa, Poso District. Descriptive study was conducted with 99 people of North Lore District. Variable in this research is knowledge and attitude of community in effort of prevention of Schistosomiasis disease. Data were collected by questionnaires. Data were analyzed using descriptive statistic. The result of descriptive statistic showed that $77.8 \%$ of respondents had good knowledge and $52,5 \%$ of respondents had good attitude in preventing Schistosomiasis. Conclusion in this research is knowledge and attitude of community in effort of prevention of disease of Schistosomiasis at Primary Health Care of Wuasa, Poso District in good category. Based on these findings, the health workers should be to raise awareness of local communities in supporting the prevention of Schistosomiasis disease.
\end{abstract}

Keywords: Knowledge, attitude, Schistosomiasis.

\begin{abstract}
Abstrak
Latar Belakang: Schistosomiasis adalah penyakit yang disebabkan oleh cacing Schistosoma japonicum yang memerlukan hewan perantara yaitu keong yang disebut Oncomelania Hupensis Lindoensis. Di wilayah kerja Puskesmas Wuasa merupakan daerah fokus keong (habitat keong) yang sebagian besar penduduknya adalah pendatang yang membuka lahan persawahan maupun perkebunan. Pemberantasan penyakit Schistosomiasis sampai saat ini belum mencapai target $<1 \%$, disebabkan masih banyak masyarakat setempat memiliki perilaku yang kurang mendukung dalam hal pencegahan. Tujuan penelitian ini adalah diketahuinya pengetahuan dan sikap masyarakat dalam upaya pencegahan penyakit Schistosomiasis di Puskesmas Wuasa Kabupaten Poso. Jenis penelitian adalah deskriptif. Variabel dalam penelitian ini adalah pengetahuan dan sikap masyarakat dalam upaya pencegahan penyakit Schistosomiasis. Pengumpulan data menggunakan kuesioner. Analisa data menggunakan analisis univariat. Populasi dalam penelitian ini adalah semua masyarakat Kecamatan Lore Utara. Pengambilan sampel menggunakan teknik
\end{abstract}


proporsional random sampling berjumlah 99 responden. Hasil analisis univariat menunjukan $77,8 \%$ responden memiliki pengetahuan yang baik dan $52,5 \%$ responden memiliki sikap yang baik dalam upaya pencegahan Schistosomiasis. Kesimpulan dalam penelitian ini adalah pengetahuan dan sikap masyarakat dalam upaya pencegahan penyakit Schistosomiasis di Puskesmas Wuasa Kabupaten Poso dalam kategori baik. Saran kepada petugas kesehatan untuk meningkatkan kesadaran masyarakat setempat dalam mendukung pencegahan penyakit Schistosomiasis.

Kata kunci : Pengetahuan, sikap, Schistosomiasis.

\section{PENDAHULUAN}

Kesehatan merupakan hasil interaksi berbagai faktor, baik faktor internal yang dari dalam diri manusia maupun faktor eksternal yang dari luar diri manusia (Notoadmodjo, 2010). Cacing Schistosomiasis tersebar dibeberapa Negara dengan spesies yang berbeda-beda, di Indonesia penyakit ini telah di temukan sejak tahun 1935 di Provinsi Sulawesi Tengah yaitu di daerah Danau Lindu Kabupaten Sigi. Pada tahun 1972 telah ditemukan daerah endemik yaitu di Lembah Napu Kabupaten Poso. Penyakit ini di tularkan melalui vector yaitu keong Oncomelania Hupensis Lindoensis yang merupakan hospes perantara cacing trematoda yang menyebabkan penyakit Schistosomiasis japonicum. (Kemenkes, 2015). Daerah endemis Schistosomiasis di Kabupaten Poso terdiri dari 5 kecamatan dengan jumlah desa sebanyak 23 desa. Berdasarkan rate kasus Schistosomiasis pada manusia pada tahun 2014 sudah mencapai target $<1 \%$ dimana pada semester pertama angka prevalensi sebesar $0,64 \%$ dan semester kedua $0,82 \%$. Pada tahun 2015 prevalensi Schistosomiasis mengalami peningkatan diatas $1 \%$ dan ini masih merupakan masalah kesehatan masyarakat. Pemberantasan penyakit Schistosomiasis sampai saat ini belum mencapai target $<1 \%$, disebabkan masih banyak masyarakat setempat memiliki perilaku yang kurang mendukung dalam hal pencegahan (Dinkes Kabupaten Poso, 2015).

Tujuan penelitian ini adalah untuk mengetahui pengetahuan dan sikap masyarakat tentang upaya pencegahahan penyakit Schistosomiasis di Puskesmas Wuasa Kabupaten Poso.

Manfaat penelitian ini adalah sebagai data untuk Puskesmas Wuasa dalam upaya meningkatkan pelayanan kesehatan dalam upaya pencegahan penyakit Schistosomiasis.

\section{METODE PENELITIAN}

Penelitian ini merupakan penelitian deskriptif untuk menggambarkan objek atau peristiwa yang bertujuan untuk mengetahui keadaan yang terjadi pada saat sekarang. Populasi dalam penelitian ini adalah masyarakat Kecamatan Lore Utara. Sampel dalam penelitian ini adalah semua masyarakat yang ada di Kecamatan Lore Utara 
Kabupaten Poso. Jumlah sampel dalam penelitian ini sebesar 99 responden.

Tekhnik pengambilan sampel secara Proporsional Random Sampling dengan kriteria inklusi: masyarakat di Wilayah Kerja Puskesmas Wuasa Kecamatan Lore Utara Kabupaten Poso yang sudah dewasa (>17 tahun), sudah tinggal di Wilayah Kerja Puskesmas Wuasa Kecamatan Lore Utara Kabupaten Poso $>6$ bulan. Kriteria eksklusi: tempat tinggal tidak permanen (menetap).

\section{HASIL PENELITIAN DAN PEMBAHASAN}

Hasil penelitian pada menunjukkan karakteristik responden dilihat dari usia menunjukkan bahwa dari 99 responden terbanyak dalam kategori usia dewasa awal (34,3\%), dilihat dari pekerjaan sebagian besar adalah petani $(40,4 \%)$, dilihat dari pendidikan sebagian besar pendidikan menengah atas (SMA) sebesar $45,5 \%$.

Tabel 1. Distribusi frekuensi berdasarkan karakteristik responden

\begin{tabular}{lcc}
\hline \multicolumn{1}{c}{ Variabel } & $\begin{array}{c}\text { Frekuensi } \\
(\mathrm{F})\end{array}$ & $\begin{array}{c}\text { Presentase } \\
(\%)\end{array}$ \\
\hline Usia: & & \\
Remaja akhir & 17 & 17,2 \\
Dewasa awal & 34 & 34,3 \\
Dewasa Akhir & 27 & 27,3 \\
Lansia awal & 15 & 15,2 \\
Lansia akhir & 3 & 3,0 \\
Manula & 3 & 3,0 \\
\hline Pekerjaan: & & \\
Mahasiswa & 2 & 2,0 \\
Honorer & 6 & 6,1 \\
Pendeta & 2 & 2,0 \\
Pensiunan & 4 & 4,0 \\
PNS & 11 & 111,1 \\
\hline
\end{tabular}

\begin{tabular}{|c|c|c|}
\hline Polisi & 2 & 2,0 \\
\hline Petani & 40 & 40,4 \\
\hline URT & 25 & 25,3 \\
\hline Wiraswasta & 7 & 7,1 \\
\hline \multicolumn{3}{|l|}{ Pendidikan: } \\
\hline Tinggi & 21 & 21,2 \\
\hline Menengah & 45 & 45,5 \\
\hline Dasar/rendah & 33 & 33,3 \\
\hline Total & 99 & 100 \\
\hline
\end{tabular}

Tabel 2. Distribusi responden berdasarkan pengetahuan dan sikap masyarakat dalam upaya pencegahan penyakit Schistosomiasis di Puskesmas Wuasa Kabupaten Poso Tahun 2017.

\begin{tabular}{|c|c|c|c|}
\hline Variable & Kategori & Frekuensi & $\begin{array}{l}\text { Persentase } \\
\quad(\%)\end{array}$ \\
\hline \multirow{3}{*}{ Pengetahuan } & Baik & 77 & 77,8 \\
\hline & Cukup & 21 & 21,2 \\
\hline & Kurang & 1 & 1,0 \\
\hline \multirow[t]{2}{*}{ Total } & & 99 & 100 \\
\hline & Baik & 52 & 52,5 \\
\hline \multirow[t]{2}{*}{ Sikap } & Cukup & 46 & 46,5 \\
\hline & Kurang & 1 & 1,0 \\
\hline \multicolumn{2}{|l|}{ Total } & 99 & 100 \\
\hline \multirow{3}{*}{$\begin{array}{c}\text { Upaya } \\
\text { pencegahan } \\
\text { penyakit } \\
\text { schistosomiasis }\end{array}$} & Baik & 9 & 9,1 \\
\hline & Cukup & 83 & 83,8 \\
\hline & Kurang & 7 & 7,1 \\
\hline Total & & 99 & 100 \\
\hline \multicolumn{4}{|c|}{ Sumber: Data primer hasil olahan data, 2017} \\
\hline \begin{tabular}{l}
\multicolumn{1}{c}{ Hasil } \\
bahwa \\
mempengarul
\end{tabular} & $\begin{array}{l}\text { peneliti } \\
\text { pendid } \\
\text { hi }\end{array}$ & $\begin{array}{ll}\text { an } & \text { me } \\
\text { ikan } & \\
& \text { pel }\end{array}$ & $\begin{array}{r}\text { nunjukkan } \\
\text { sangat } \\
\text { ngetahuan }\end{array}$ \\
\hline \multicolumn{3}{|c|}{ masyarakat tentang } & penyakit \\
\hline
\end{tabular}

Selain itu usia dapat mencerminkan pengalaman dan kematangan jiwa dalam mampu berfikir kreatif, penelitian ini dari 99 responden lebih dominan responden yang memiliki usia 26-35 tahun yaitu sebanyak $34,3 \%$, rentang usia tersebut merupakan 
dewasa awal. Sehingga memungkinkan seseorang berpengetahuan baik.

Status pekerjaan juga mempengaruhi pengetahuan, dimana jumlah responden dominan sebagai petani yaitu sebanyak $40,4 \%$, hal ini menunjukkan bahwa responden yang bekerja sebagai petani lebih dominan kurang terpapar informasi. Namun tidak semua responden yang bekerja sebagai petani kurang memperoleh informasi, yang ditandai dengan pengisisan kuesioner bahwa ada beberapa responden memiliki pengetahuan yang baik tentang Schistosomiasis.

Menurut Notoatmodjo (2012) bahwa pengetahuan merupakan hasil dari

tahu dan ini terjadi setelah orang melakukan penginderaan terhadap suatu objek tertentu. Maksudnya responden memiliki pengetahuan tentang penyakit Schistosomiasis setelah melakukan penginderaan, baik melalui mata dengan melihat dan telinga dengan mendengar informasi tentang penyakit Schistosomiasis.

Pengetahuan

sangat

mempengaruhi sikap masyarakat tentang penyakit Schistosomiasis, hal ini sesuai dengan pernyataan Notoatmodjo (2007) bahwa dalam penentuan sikap, pengetahuan memegang peranan penting. Dengan pengetahuan, manusia dapat mengembangkan apa yang diketahuinya dan dapat mengatasi kebutuhan kelangsungan hidup sehingga akan mempengaruhi sikap seseorang.
Hasil penelitian tentang pengetahuan dan sikap sebagian besar responden memiliki pengetahuan yang baik sedangkan hasil penelitian dari sikap sebagian besar responden memiliki sikap yang positif atau baik sehingga upaya pencegahan yang dilakukan responden sudah cukup baik. Sedangkan sebagian responden memiliki upaya pencegahan yang kurang baik ini disebabkan kesadaran masyarakat untuk mencegah penyakit Schistosomiasis masih kurang seperti tidak mau mengumpulkan tinja untuk diperiksa setiap 6 bulan sekali, tidak mau minum obat Schistosomiasis dengan alasan efek samping yang ditimbulkan, tidak menggunakan APD (alat pelindung diri) saat bekerja atau melewati daerah fokus keong dengan alasan dapat menghambat pekerjaan dan tidak mau mengikuti penyuluhan yang diadakan oleh petugas kesehatan serta tidak mau mencari tahu informasi tentang Schistosomiasis.

Menurut teori Perry \& Potter (2005), pencegahan penyakit merupakan komponen penting dalam pelayan kesehatan. Perawatan pencegahan melibatkan aktivitas peningkatan kesehatan termasuk program pendidikan kesehatan khusus, yang dibuat untuk membantu klien menurunkan resiko sakit, mempertahankan fungsi yang maksimal dan meningkatkan kebiasaan yang berhubungan dengan kesehatan yang baik. Upaya pencegahan penyakit Schistosomiasis dilakukan untuk menurunkan angka prevalensi kejadian 
Schistosomiasis. Upaya pencegahan penyakit Schistosomiasis dalam penelitian ini adalah tindakan yang perna dilakukan oleh responden dalam mencegah penyakit Schistosomiasis.

\section{SIMPULAN}

Hasil penelitian menunjukkan sebagian besar usia masyarakat di wilayah kerja Puskesmas Wuasa Kabupaten Poso dalam kategori usia dewasa awal, pekerjan petani, pendidikan setingkat sekolah menengah atas. Terlihat dari pengetahuan, sikap, dan upaya pencegahan penyakit Schistosomiasis oleh masyarakat di wilayah kerja Puskesmas Wuasa Kabupaten Poso Tahun 2017 dalam kategori kategori baik.

\section{SARAN}

Disarankan agar Puskesmas Wuasa selalu berkoordinasi dengan petugas Schsitosomiasis dan perangkatperangkat Desa serta instansi-instansi terkait di Kecamatan Lore Utara untuk mengadakan penyuluhan kesehatan tentang Schsitosomiasis kepada seluruh lapisan masyarakat. Untuk lebih meningkatkan kesadaran bagi masyarakat setempat baik dan bagi masyarakat asli maupun masyarakat pendatang dalam mendukung proses pencegahan dan penanggulangan penyakit Schistosomiasis.

\section{UCAPAN TERIMA KASIH}

Ucapan terima kasih kami sampaikan kepada STIK Indonesia Jaya
Palu yang telah memberi dukungan dalam bentuk materi maupun moril, serta seluruh responden, instansi pemerintahan dan perangkat desa dalam wilayah kerja Puskesmas Wuasa.

\section{DAFTAR PUSTAKA}

Dinas Kesehatan Provinsi Sulawesi Tengah. (1992). Pemberantasan Shcistosomiasis di Sulawesi Tengah.

Dinas Kesehatan Provinsi Sulawesi Tengah. (2015). Buku Saku Shcistosomiasis.

Dinas Kesehatan Provinsi Sulawesi Tengah. (2015). Profil Kesehatan Dinas Kesehatan Sulawesi Tengah.

Dinas Kesehatan Kabupaten Poso. (2015). Profil Kesehatan Kabupaten Poso, Sulawesi Tengah.

Kemenkes RI. (2015). Pedoman Pengendalian Schistosomiasis. Jakarta. Ditjen PP dan PL.

Notoadmodjo S. (2010). Promosi Kesehatan. Jakarta: Rineka Cipta

Notoadmodjo S. (2011). Kesehatan Masyarakat Dan Seni. Jakarta: Rineka Cipta

Notoadmodjo S. (2012). Promosi Kesehatan Dan Perilaku Kesehatan. Jakarta: Rineka Cipta.

Notoadmodjo S. (2014). IImu Perilaku Kesehatan. Jakarta: Rineka Cipta.

Potter, P.A. and Perry, A.G. (2005) Buku Ajar Fundamental Keperawatan: Konsep, Proses, dan Praktik. Edisi 4, Volume 1, Alih Bahasa, Asih, Y. EGC, Jakarta. 